\title{
El uso de baremos en la valoración de daños personales. La reforma del baremo de tráfico
}

\section{Introducción}

La cuantificación y la indemnización de daños personales debe apoyarse en el empleo de baremos. No es esta una afirmación discutible, sino que tiene un valor absoluto. El empleo de baremos aporta numerosas ventajas, entre las que cabe destacar las siguientes:

- Facilita la comprensión del informe pericial para el no iniciado. Transformar la compleja red de secuelas que un paciente puede presentar, sus consecuencias, interacciones y evoluciones futuras, en una cifra, o en varias combinadas, situadas dentro de una escala concreta (siendo la más frecuente de 0 a 100), permite al lector obtener de inmediato y con suma facilidad una imagen resumen bastante cercana a la realidad sobre la situación del paciente y sus posibles consecuencias, del verdadero quantum que el experto pretende analizar y expresar en su informe.

- Introduce un elemento común que uniformiza los criterios de cuantificación, aproximando los casos de valoración a lo más cercano posible al concepto de Justicia, de tal modo que casos similares sean tratados de igual forma.

- Facilita los acuerdos amistosos fuera de la vía judicial, descargando considerablemente el trabajo de la Administración de Justicia, acelerando el acceso de la víctima a la compensación económica y la atención de otras necesidades perentorias en los casos más graves, como la atención especializada continuada, la adaptación del domicilio y la eliminación de barreras arquitectónicas, la adecuación del transporte personal mediante la adquisición de un vehículo adaptado, y un largo etcétera.

- Permite a mutuas y compañías aseguradoras hacer previsiones económicas precisas y esenciales para el adecuado futuro funcionamiento de estas entidades esenciales en el sistema nacional que permite la compensación de daños en nuestro país.
Muchas de estas afirmaciones no son originales, y aún menos mías, sino que ya venían debidamente expuestas en la exposición de motivos de la Ley 30/95, que mostraba en su Anexo el primer baremo (sistema) moderno de compensación de daños personales (en este caso para daños derivados de accidentes de tráfico a compensar por el seguro obligatorio de responsabilidad civil de los vehículos de motor) que se aplicó en España, después de la nefasta última actualización del "baremo español" de doce categorías realizada mediante el Real Decreto 1575/85.

Su aparición supuso para nuestro país una verdadera revolución, que introdujo la valoración y la compensación de daños en la práctica habitual médico-legal con profunda intensidad, dando lugar a una eclosión de sociedades y asociaciones profesionales, revistas, libros, encuentros profesionales y congresos, etc., que no fueron más que la expresión del éxito de la herramienta publicada. Era evidente que conseguía muchos de los objetivos planteados, y comenzó a aplicarse con profusión no sólo en los casos de cuantificación de secuelas derivadas de accidentes de tráfico, sino también en otros muchos casos ajenos a estos para los que se había ideado, y en muchas ocasiones por petición directa de los profesionales del derecho, e incluso por Jueces y Tribunales. Hoy en día es aceptado como herramienta que permite un mejor informar, siempre sin carácter vinculante para el juzgador y adaptado a las circunstancias y características del asunto en cuestión diferente de un accidente viario. Incluso se produjo un amplio desarrollo de aplicaciones informáticas que supuestamente permitían a cualquier interesado conocer la valoración de un caso con la simple introducción de la relación de secuelas de la persona interesada.

\section{La esclavitud del baremo}

Un éxito de tales dimensiones que, no olvidando que existen otros baremos de aplicación obligatoria en nuestro Ordenamiento (por ejemplo, para la compen-

\section{Hernández Cueto}

Departamento de Medicina Legal, Universidad de Granada.

Correspondencia:

Claudio Hernández Cueto Departamento de Medicina Legal, Toxicología y Antropología Física. Facultad de Medicina. Universidad de Granada. Avda. de Madrid, 11. 19071 Granada.

E-mail: chc@ugr.es 
sación de secuelas no invalidantes en el ámbito de la Seguridad Social), hace que hoy en día empleemos la palabra "baremo" y no sea necesario (como me ha sucedido a mí en el título de este subapartado) aclarar que nos estamos refiriendo al de tráfico concretamente, en sus versiones de 1995, 2003 o 2004; y que nos ha llevado a la esclavitud de un empleo cuasi obligatorio del baremo en cualquier caso de daños personales fuera de los derivados de accidentes de tráfico a compensar por el seguro de responsabilidad civil obligatorio, donde, como es bien sabido, es de empleo obligatorio dentro del informe pericial correspondiente.

No quiero transmitir con mis palabras que me parezca mal ese empleo. Al contrario, creo que debe ser empleado cualquier elemento que permita al lector del informe médico-legal una mejor comprensión, pero no con el estrecho corsé que ahora se impone, ni con la estrechez de miras con que frecuentemente se hace.

El baremo de tráfico ahora empleado, contenido en este momento en el Anexo del Real Decreto Legislativo 8/2004, es de aplicación obligatoria por parte del médico experto en los casos en que fue previsto: la indemnización de los daños derivados de accidentes de tráfico que deban ser abonados a través del seguro obligatorio de responsabilidad civil de vehículos a motor. $Y$ sin ser su resultado vinculante en modo alguno para el juzgador por razones variadas, pero destacando dos elementos esenciales: el libre arbitrio, como característica esencial del sistema judicial, no puede ser alegremente eliminado, y en segundo lugar, ese criterio personal del juzgador-también experto en la materia gracias a su continuo ejercicio profesionalpermite completar aspectos no contemplados en una herramienta como un baremo, pero que forman parte esencial de la compensación debida a la víctima: los daños morales, la pérdida de la capacidad de disfrute del placer, la modificación peyorativa de la capacidad de relación con el entorno y los demás, y muchos más.

Fuera de ese territorio, el baremo pierde la obligatoriedad, pero desde mi punto de vista no pierde la utilidad y sigue siendo una buena herramienta orientadora que emplear como un ítem añadido "para mejor informar". Podría emplearse cualquier otro de los muchos existentes, y este en concreto se utiliza con más frecuencia por ser el más familiar tanto para los profesionales de la Medicina como para los del Derecho.

No obstante todo lo señalado, se ha producido una dependencia excesiva del baremo de tráfico, de tal modo que parece académicamente obligado emplear- lo en cualquier caso de valoración médica del daño corporal. Nos hemos convertido en esclavos de un documento ideado para nuestro servicio, no al revés. Parece que un informe de valoración de daños personales no es correcto, ni de calidad, si no se emplea el baremo y se incluyen los correspondientes puntos. Craso error. Un informe médico legal sobre valoración del daño puede ser de la máxima calidad científica sin emplear el baremo de tráfico, e incluso sin emplear baremo alguno. Muchos podrán decir que es esta una afirmación simplista con la que, por supuesto, están de acuerdo, pero véase la realidad y se comprobará que sucede el fenómeno antes señalado: parece que es imposible valorar sin emplear el baremo.

Esta esclavitud se extiende a otro error superlativo: el baremo y el resultado con él obtenido se convierten en conclusión fundamental (en muchas ocasiones, única) de los informes periciales de valoración de daños personales. Como digo, el error es garrafal, y se comete una y otra vez. Un baremo es una herramienta, y como tal es un medio, no pudiendo ser nunca un fin. Es decir, la cifra en puntos con él obtenida es un dato añadido a considerar, pero no el único ni el más importante. Atendiendo a la necesidad de una compensación íntegra de los daños, como nuestra doctrina ha establecido reiteradamente desde hace mucho tiempo, la valoración también debe ser integral y no puede limitarse a la simple consideración de días de baja -hospitalarios o no, impeditivos o no- y de secuelas, y su transformación en un valor numérico. La valoración de daños es personal; se trata de un individuo concreto, con unas características, obligaciones y actividades determinadas, y merece una valoración concreta, del daño y sus consecuencias, dentro del ámbito exclusivo de esa persona, teniendo en cuenta su sexo, edad, profesión, situación familiar, vida de ocio, vida de relación, etc., para acceder así a esa valoración integral médico-legal del daño que permitirá el establecimiento de un quantum indemnizatorio realmente cercano a la compensación integral exigida, y eso ningún baremo -ni siquiera nuestro baremo de tráfico- lo permite. Como consecuencia, el informe pericial que concluye con la aplicación del baremo es un informe cojo, incompleto.

\section{Versiones del baremo. La debida actualización}

Modernizar la herramienta a emplear es obligado. Así se viene reclamando desde hace tiempo. Eso sucede ahora con el baremo de tráfico y así ocurrió con anterioridad con las versiones de 1995, 2003 y 2004. 
Cuando se produjo la modificación de la versión inicial de 1995, tanto las compañías aseguradoras como las asociaciones de víctimas y la Administración se pusieron de acuerdo en la necesidad de una actualización, pero no así en los aspectos a reformar.

La drástica reducción en el número de siniestros ocurrida en España a finales del siglo pasado y comienzos del actual, junto con un aumento medio del parque móvil de un $65 \%$, justificaba incrementar las indemnizaciones (en forma de valor de los puntos, valor de los periodos de baja y de los factores de corrección) a criterio de las víctimas y también del Estado. Aún más, a la vista de que las aseguradoras estaban alcanzando beneficios cercanos al $10 \%$, frente al $2-3 \%$ de media en la UE, y de que en los países afines esas cifras indemnizatorias eran muy superiores (el 300\% en Alemania, el 150\% en Italia, etc.), la UNESPA adujo que el sistema español incluía en el montante de la compensación elementos no considerados en otros países, como por ejemplo el lucro cesante, gran parte del daño patrimonial sin tener que probarlo, y otros.

La reforma de 2003 supuso más una adecuación al Consorcio de Seguros que otra cosa, con una reducción de los ítems a considerar indemnizables en la relación de secuelas y una disminución de las puntuaciones asignadas en muchos casos (la reducción en la patología cervical, el cambio de criterio y de puntuaciones en las lesiones de los miembros superiores e inferiores, etc.).

Sin embargo, no hay que olvidar que el baremo de tráfico, además de una herramienta para facilitar transacciones económicas donde las aseguradoras tienen mucho que decir, es sobre todo un instrumento de justicia social y solidaridad, por lo que debe ser mejorado y adaptado a la realidad económica y social del país, atendiendo a todas las partes afectadas.

Así parece estar sucediendo ahora con el proyecto de reforma en el que han tenido representación la UNESPA, los Ministerios de Economía y de Justicia, juristas y asociaciones de víctimas (AESLEME, ASPAYM, Fedace, etc.).

Sin pretender entrar en un análisis pormenorizado del contenido del nuevo baremo previsto en el proyecto, lo que supera con mucho las pretensiones de este texto, sí conviene señalar los aspectos esenciales que la modificación puede conllevar:

- Un incremento de las indemnizaciones del 10\% al $15 \%$, lo que debe ser siempre bien recibido y que, aunque no nos aproxime a los ideales previstos en otros países de nuestro ámbito, y ni siquiera al pretendido $27 \%$ planteado por las asociaciones, se adapta algo mejor a la realidad de nuestra sociedad.

- Se mejoran especialmente las indemnizaciones para las lesiones graves, lo que tampoco ha sido un gran esfuerzo por parte del sector asegurador, dado que estas ocupan un mínimo espacio del total de casos.

- Se introducen nuevos conceptos de indemnización, como las intervenciones quirúrgicas, los gastos futuros de asistencia sanitaria, las prótesis, las ayudas de terceras personas, etc.

- El derecho a una total indemnización para los menores de 14 años, a los que no se les podrá aplicar criterios de reducción por culpabilidad o coparticipación.

- La separación del daño moral y el daño patrimonial.

- La creación de tablas para la valoración del lucro cesante futuro.

- La inclusión de la valoración del trabajo doméstico y para aquellas víctimas que sufran lesiones permanentes tras un accidente, aunque aún no hayan desarrollado actividad laboral alguna.

Adolece, a criterio de las víctimas, de falta de claridad y de múltiples y complejas reglas; necesita para su empleo especialistas muy formados, y carece de la necesaria simplicidad para ser entendido por cualquiera de los afectados.

Los aspectos específicos de contenido de la nueva versión merecen un profundo y amplio estudio que realizar en otro momento, pero pueden destacarse aquí las siguientes novedades:

- Parece que la relación de secuelas se ha reestructurado con mejor criterio médico, corrigiendo algunos errores graves anteriores, aunque manteniendo otros (por ejemplo, la consideración de las amputaciones de los dedos es excesiva, compleja y demasiado amplia).

- Sigue manteniéndose aparte la consideración del perjuicio estético, lo que, según mi criterio, es francamente mejorable, pero ha habido -al menos- cierta mejora terminológica.

- Es de considerar un acierto que la estimación del valor económico de los puntos no se haga ya de acuerdo con intervalos de puntuación obtenida e intervalos de la edad de la víctima, sino permitiendo individualizar caso a caso.

- La inclusión de la indemnización de la asistencia sanitaria futura es simplemente un acierto desde el punto de vista médico-legal. 
- La consideración de la ayuda de tercera persona ha mejorado, pero creo que se ha hecho en exceso y complicándola innecesariamente.

- En cambio sí es un acierto la minuciosidad de las tablas que consideran la valoración económica de la invalidez permanente en sus distintos grados.

- La tabla para la indemnización del periodo de baja me sigue pareciendo, a pesar del total cambio de criterios, complicada y errónea. Sistemas como el empleado en otros países afines al nuestro, en forma de porcentaje temporal que se va reduciendo conforme se alcanza la curación o la estabilización, me parecen más sencillos y justos.

- La consideración de la pérdida de autonomía se venía reclamando desde hacía mucho, y como consecuencia es positivo que ahora se acepte, sobre todo en casos de individuos añosos con afecciones limitantes después del traumatismo sufrido.

De todos modos, para apreciar estos extremos, y como antes señalaba, será necesario conocer el texto definitivo y realizar un análisis mucho más detenido que el que aquí, por razones de extensión, puedo hacer.

Acaso precisará, y es de esperar que la tenga, una adecuada y profunda actualización científica de la relación de secuelas, tal como solicitaron diversos grupos políticos en las correspondientes comisiones celebradas el año pasado en el Congreso de los Diputados. La terminología empleada es muy antigua, y los criterios de clasificación de secuelas han sido ampliamente superados hace ya años; existen lapsus inadmisibles, el dolor no es debidamente considerado, aceptado para algunas secuelas y simplemente olvidado para otras muchas; eliminar el sistema de englobar secuelas que impone una más genérica, encorsetando la valoración y con el exclusivo fin de reducir la compensación; la valoración del perjuicio estético merece una profunda revisión que supere con mucho el sistema hasta ahora utilizado; los factores correctores son insuficientes, y muchas más consideraciones.

Finalmente, las asociaciones de víctimas han incluido una última petición: quitar al baremo su exclusividad para los accidentes de tráfico y extenderlo a los accidentes en general, algo que en la práctica está siendo cada vez más frecuente, pero que no está debidamente regulado y que exigiría del texto del baremo algunas precisiones para accidentes ferroviarios, grandes catástrofes aéreas, etc. Ello determinaría que casos como los de Chinchilla en 1996, el metro de Valencia en 2003 o el accidente ferroviario de Santiago de Compostela en 2013, no estuviesen muchos años en los tribunales y las víctimas sin recibir las indemnizaciones.

Debemos quedar, por tanto, a la espera de este nuevo documento, y comprobar en qué medida satisface las necesidades planteadas, pero sin olvidar, como al inicio señalaba, que no se trata más que de una herramienta, útil y cada vez mejor desarrollada, pero tan sólo una herramienta que no podrá satisfacer nunca las necesidades de la debida actuación pericial, la cual deberá quedar siempre en manos del correspondiente médico experto.

\section{Bibliografía}

- Borrador del Sistema para la Valoración de los Daños y Perjuicios causados a las personas en accidentes de circulación. Grupo de Trabajo para la reforma del Sistema. Madrid: INESS; 2014.

- Holgado J. El nuevo baremo les vuelve locos. Capital Madrid, 15 de julio de 2014.

- $\quad$ Ley 30/1995, de 8 de noviembre, de Ordenación y Supervisión de los Seguros Privados. Boletín Oficial del Estado, número 288, de 9 de noviembre de 1995 , pp. $32480-32567$.

- Menéndez JM. Hay que mejorar las indemnizaciones. Tráfico y Seguridad Vial. 2010;205:35-38.

- $\quad$ Real Decreto Legislativo 8/2004, de 29 de octubre, por el que se aprueba el texto refundido de la Ley sobre responsabilidad civil y seguro en la circulación de vehículos a motor. 